\title{
Erratum to: Analysis of the Pathology Section of the OITE Will Aid in Trainee Preparation
}

\author{
Frank J. Frassica MD, Derek F. Papp MD, Edward F. McCarthy MD,
}

Kristy L. Weber MD

Published online: 21 January 2016

(C) The Association of Bone and Joint Surgeons( 2016

\section{Erratum to: Clin Orthop Relat Res (2008) \\ 466:1323-1328 \\ DOI 10.1007/s11999-008-0235-2}

In the study, "Analysis of the Pathology Section of the OITE Will Aid in Trainee Preparation" the middle initials of three coauthors were incorrectly omitted from publication. Their names, Derek F. Papp MD, Edward F. McCarthy MD, and Kristy L. Weber MD are spelled correctly with a middle initial here and above.

The authors apologize for the error.

The online version of the original article can be found under doi:10.1007/s11999-008-0235-2.

F. J. Frassica ( $\bigotimes)$, D. F. Papp, E. F. McCarthy, K. L. Weber Department of Orthopaedic Surgery, Johns Hopkins University, 601 North Caroline St., Baltimore, MD 21287, USA

e-mail: ffrassi@jhmi.edu

F. J. Frassica, D. F. Papp, K. L. Weber

Department of Oncology, Johns Hopkins University, Baltimore,

MD, USA

E. F. McCarthy

Department of Pathology, Johns Hopkins University, Baltimore,

MD, USA 